WJ. Henderson

\title{
Digter en gehoor in Alexandrië
}

\begin{abstract}
After a historical introduction, this aricle cxamines the fom, context and manner in which Greek poetry was communicated in Alexandria in Egypt during the 3rd to Ist century B.C. The poety was written for a highly selected audience, centred around the library and court of the Ptolemy, and this detenmined the nature of both the poetry and its 'publication' or communication to the target audience.

The most significant aspects of the poetr are: its heightened literary style; the transition from a sung to a recited text; the shifting of the place of communication from aristocratic banquet and public area during the previous period of the city-state to the cxclusive audience of the nuler's palace or the literan coteric; the use of enudite refercnce in the poem, increased experimentation by the poets in form, theme and style; and the strong sense and pursuit of individualism.
\end{abstract}

Die Hellenistiese Periode in die Griekse kultuurgeskiedenis vorm 'n magtige brug tussen die Griekse en Romeinse letterkunde (Hutchinson, 1988:1). Daar is egter vir die hedendaagse literatuurwetenskaplike ander redes vir die belangrikheid van hierdie fase in die literatuurgeskiedenis - redes wat die studie daarvan nodig maak. In hierdie artikel belig ons etlike van die aspekte en verskynsels ten opsigte van die poësie in Alexandrië wat in resente literatuurwetenskaplike problematiek relevant geword het: die konteks en kommunikasie van die poëtiese teks, die oorgang van 'n mondelinge na' 'n geskrewe kultuur en die verhouding van die digter tot sy gehoor. Die behandeling hier kan net oorsigtelik wees: analises van die Griekse tekste en bronne sou die aanbieding onnodig belaai. Die teikengehoor moet immers in gedagte gehou word.

\section{Die historiese konteks}

\subsection{Polis en kosmopolis}

Die bakermat en bestaansomgewing van die vroeë Griekse epos, drama en liriek, naamlik die polis of stadstaat, het teen die einde van die 5de eeu v.C. begin verbrokkel. Stryd om die heerskappy (hegemonía) van Griekeland het eers Atene (404), Sparta (371) en toe Thebe (362) se politieke en militêre mag sien kwyn. Teen 338 was Philippos van Macedonië in beheer van die hele Griekeland. Na sy dood in 336 het sy seun Alexander die veroweringswerk verder gevoer. Na finale onderwerping van die opstandige Griekse stadstate in 335 het hy op 'n veroweringstog na die Ooste vertrek. Na elf jaar (334-323) het 
hy 'n ryk tot stand gebring wat Griekeland, Egipte, Siriê en die antieke Persië ingesluit het. Aan hierdie kultuurwêreld van c. 300 tot 31 v.C. is die benaming "Hellenisties" deur Johann Gustav Droyssen (1808-1884) gegee (Lesky, 1966:642).

Oral is die Griekse kultuur en taal versprei en 'n nuwe wêreld geskep. Die polis met sy beperkte burgergetalle, sy geslote politieke stelsel waarin elke burger homself na die beste van sy vermoë en talent kon laat geld, het verdwyn. Dit is vervang deur 'n ope, kosmopolitiese samelewing van verskillende volke, elk met 'n eie kultuur, taal en gewoontes. Alexandrië was so 'n stad waarin Egiptenare, Grieke, Siriërs, Jode en Perse gewoon het. Daar word geskat dat die bevolking van Alexandrië 300000 persone (uitgesluit die slawe) beloop het. Die monargiese heersers het hulle reg om te regeer op dinastiese oorerwing en goddelike gesag gebaseer. In die groot Hellenistiese stede, soos Alexandrië, Pergamon en Antiochië, het die konings as beskermhere van die kunste en wetenskappe opgetree; dit was nie meer in die hande van die volk (dêmos) nie. Die Ptolemeë het regeer deur middel van 'n uitgebreide burokrasie van amptenare wat aangestel eerder as verkies is (Tarn \& Griffith, 1978:126-209). Die werking van hierdie groot burokrasie het sterk gesteun op geskrewe dokumentasie en rekordhouding. Dit weer, veronderstel 'n wydverspreide geletterdheid onder amptenare en gewone burgers (Easterling, 1985:17).

Daar is al aangetoon dat in die transformasie van polis na kosmopolis daar 'n hoë mate van kontinuiteit in gees, mentaliteit en aktiwiteite was (Schneider, 1967/69: I, 3-19). Tog was dit vir die gewone burger 'n onpersoonlike, verwarrende wêreld wat gedreig het om hom as individu te verswelg (Susemihl, 1965:I,1-10; Couat, 1968:515-520).

Man as a political animal, a fraction of the polis or self-governing city state, had ended with Aristotle; with Alexander begins man as an individual. (Tarn \& Griffith, 1978:79.)

Die reaksie teen hierdie bedreiging was die opbloei van die individualisme.

\subsection{Die Mouseion in Alexandrië}

Met die verbrokkeling van Alexander se wêreldryk na sy dood in 323 v.C., en veral ná Alexander se militêre oorwinning by Issos in 302 het die stad se roemryke geskiedenis as kultuursentrum van die Hellenistiese periode begin. Ptolemaios I Sotêr (regeer 305-285) en sy seun, Ptolemaios II Philadelphos (regeer 85-247), stig die beroemde twee biblioteke en die Mouseion, 'tempel van die Muses', in Alexandrie. Al is daar onsekerheid oor wie wat gestig het (kyk Susemihl, 1965:I,335-344; Couat, 1968:1-27; Wright, 1932:46-48; Lesky, 1966:3), kan die idee en aanvanklike uitvoering gekoppel word aan Demetrios van Phaleron se aankoms in Egipte in 290 na sy verdrywing uit Atene sewentien jaar vroeër (307). Hierdie geleerde en verfynde kultuurmens het Atene nog 'n kultuursentrum laat bly onder Macedoniese beheer, en na sy verwerping deur die Ateners, het hy sy talente en idees saam met hom geneem.

Die Mouseion, wat in die paleisgronde gestaan het, het die middelpunt van Griekse intellektuele en artıstieke aktiwiteit geword. Filosowe, digters, literatore, skrywers, geograwe, matematici, medici en natuurwetenskaplikes is persoonlik deur die Ptolemaios hierheen genooi en van alle fasiliteite en lewensmiddele voorsien (kyk verder Tarn \& Griffith, 1978:268-324). Kuns en wetenskap het saam gedy in 'n unieke simbiose. 
Onder 'n reeks beroemde bibliotekarisse tussen 284 en 145 v.C., naamlik Zenodotos van Efese (c. 284-c.260), Apollonios van Rhodos (c. 260-247), Eratosthenes van Kurene (c. 247194), Aristophanes van Bisantium (c. 194-180), Apollonios Eidographos (c. 180-153) en Aristarchos van Samothrakië (c. 153-145) (kyk Couat, 1968:28-58), het Alexandrië die leidende rol in die destydse intellektuele en kunslewe gespeel. Onder hulle leiding en na hulle voorbeeld is tallose tekste van vroeëre skrywers en digters versamel, geklassifiseer en gekommentarieer. Dit word gemeld dat in 285 v.C. daar 200000 of 490000 boekrolle (volumina) was (Eusebios, Praeparatio Evangelica 350B; Tzetzes, Prolegomenon de comoedia) wat in 47 v.C. tot 700000 gegroei het. In een stadium het die groot biblioteek van die Mouseion 400000 volumes gemengde en 90000 enkelwerke bevat, terwyl die kleiner biblioteek van die Serapeion 42800 boekrolle besit het, insluitend kopieë (Susemihl, 1965:I,342; Couat, 1968:20; Pfeiffer, 1968:100-102; Blum, 1977: kol. 140-144, 156-161). 'n Massa krities-teoretiese werk oor metriese, taalkundige, inhoudelike en stilistiese aangeleenthede het ontstaan wat die begin van die wetenskap van filologie was. Kallimachos (c. 305-c. 240 v.C.), leidende digter van die tyd wat aanvanklik in die biblioteek gewerk het, het 'n lys van al die belangrike skrywers en hulle werke in 120 boekrolle opgestel. Hierdie katalogus, wat die Pinakes (Tabelle) geheet het, het die outeurs in elke genre alfabeties ingedeel, en biografiese besonderhede oor die outeurs en aantekeninge oor die lengte en egtheid van hul werke verskaf.

Alhoewel dit nie behoue gebly het nie, is oral tekens van die groot invloed van hierdie eerste kritiese literêre geskiedenis. Die groot hoeveelheid boekrolle wat in die Mouseion en biblioteek bewaar is, is 'n sprekende aanduiding van die geweldige toename in die aantal lesers, 'professioneel' en 'amateur', in hierdie tyd en plek. Die woestynsand van Egipte het reeds 'n skat van literêre en nie-literêre materiaal op papirus opgelewer en doen dit steeds, en dit is maar 'n uiters klein deel van die eens florerende mark vir boekrolle (kyk verder Easterling, 1985:29-41; Bullock, 1985:541-542, 549-550). Ons weet van meer as eenduisend skrywers uit hierdie periode, maar net 'n uiters klein deel van hulle enorme produksie het behoue gebly.

\section{Die vorm van kommunikasie}

Die vorm van kommunikasie of 'publikasie' van poësie het in die Griekse kultuurwêreld verskeie fases deurgegaan: 'n fase van suiwer mondelinge skepping en voordrag wat teen die middel-8ste eeu v.C. aan die kwyn was; 'n oorgangstadium van toenemende gebruik van skrif in komposisie, maar van steeds mondelinge, lewendige voordrag voor 'n gehoor gedurende die 8ste tot laat-5de eeu v.C.; en 'n fase waarin die letterkunde byna uitsluitlik as geskrewe, geleesde teks geskep en gekommunikeer is - 'n fase wat vanaf die Hellenistiese tyd al hoe sterker geword het. In werklikheid het die antieke mens egter nooit die vlak van geletterdheid van die moderne mens bereik nie.

Die geletterdheid van die Hellenistiese periode is die klimaks van 'n lang proses van ontwikkeling vanaf' $n$ preliterêre, suiwer mondelinge kultuur voor die 8 ste eeu v.C. Vir vyfhonderd jaar het die gebruik van die alfabet en daarmee die vermoë om te lees en te skryf in die Griekse wêreld versprei totdat die aanvanklike 'liedkultuur' (song culture) 'n volwaardige 'boekkultuur' (book culture) geword het (Herington, 1985:3 e.v.; Davison, 1968:86-128; Knox, 1985:1-16; Easterling, 1985:16-41). Teen die tyd van Plato en Aristoteles in die 4de eeu is boeke (= boekrolle), biblioteke, boekwinkels, die lees en bespreking van geskrewe werke in vers of prosa redelik algemeen. Met die Lukeion 
(Latyn: Lyceum) wat Aristoteles in Atene gestig het, ontstaan die eerste werklike institusionele biblioteek, waar boeke vir navorsing versamel is (Knox, 1985:13). In sy eie werk, die Retorika (1407B), bespreek Aristoteles probleme van die skryfwyse van 'n teks, soos byvoorbeeld woordverdeling, aksentplasing en interpunksie. Hiermee word dit die eerste werk waarin die kritiese uitsprake op die literêre werk as geskrewe eerder as aangehoorde teks gerig is (Knox, 1985:13).

Die Grieke het deurgaans, vanaf die oorwegend mondelinge fase van hulle kultuur in die Argaïese en Klassieke tydperke, tot in die hoogs geletterde fase in die Hellenistiese tydperk hardop gelees, asof die leeshandeling eintlik 'n voordrag voor 'n soort gehoor was (Knox, 1985:7, 14). Reeds in 1893 het Reitzenstein (1893:1) dit gestel:

\begin{abstract}
Wir wissen, dass der alexandrinische Dichter für buchmässige Verbreitung arbeitet, wie der moderne; aber wir dürfen nicht vergessen, dass er immer einen Vortrag fingiert, und lebendig wird uns sein Werk nur. wenn wir es wirklich vorgetragen denken ...
\end{abstract}

Die gedigte is nog bewustelik geskep om gehoor eerder as om op byvoorbeeld 'n papirusvel gesien te word. Daar is egter gevalle waar dit duidelik is dat die gedig se effek grotendeels daarvan afhang dat die leser dit op die bladsy moet kan sien. Sulke gevalle is die sogenaamde carmina figurata, 'figuurgedigte' of 'patroongedigte', waar die gedig die vorm van die onderwerp probeer weergee op die bladsy. So is daar "Die byl" (pélekus), "Die eier" (ôn) en "Die vlerke" (ptéruges). Die Anthologia Palatina bevat heelwat verwysings na skrif $(9.162,174,175,350,401,524-5)$ en geskrewe tekste $(5.191,215 ; 7.697 ; 9.171,186,192,239$, $251,434,540,542 ; 12.74)$.

Teen die laat-4de eeu v.C. was die lewendige voordrag van 'n gedig voor 'n gehoor nie meer die dominante wyse van kommunikasie wat dit in die vorige eeue was nie (Knox, 1985:13-14). Daar was steeds lewende voordragte. Van 'n epigram van Alkaios van Messene (Anthologia Palatina 16.7) leer ons van 'n Thebaanse fluitspeler wat liedere soos "Die vernietiging van Troje", "Die geboorte van Dionusos" en "Die Trojaanse perd" sou begelei het (Webster, 1964:235). Dieselfde digter verwys in 'n ander epigram (AP 7.412) na die voordrag van 'n gedig van 'Timotheos deur 'n kitharôdos genaamd Pulades (Webster, 1964:235).

Die kompleksiteit van die situasie kan geillustreer word aan die hand van twee gedigte van dieselfde digter. Uit Theokritos se Idille 14.59-64 is dit duidelik dat die gedig gerig is aan die Ptolemeër, wat waarskynlik in die gehoor by die eerste voorlees van die gedig teenwoordig was (Bullock, 1985:580). Alles dui op 'n lewendige voordrag. Daarteenoor is Idille 16, waarin verwys word na die papirus waarop die gedig geskryf is, 'n 'leesgedig'.

Now Theocritus presents a text that cannot possibly be sung and might not even be recited by the poet himself - mere words on a page. Poetry had lost its music. The poet would be foolish to pretend otherwise, nor can he put himself forth as an accomplished musician, choreographer, and choirmaster. (Grifliths, 1979:24; kyk die hele analise 9-50.)

Nogtans was die 'publikasie' van 'n literêre werk allermins vergelykbaar met moderne praktyk. Skrywers het steeds eers hul gedigte voorgedra in die paleis van die Ptolemeër of tydens 'n sumposion. Daarna het hulle enkele eksemplare van hulle werke (deur hulself of hulle slawe gekopieer?) aan belangstellendes verskaf (Isokrates, Panathenaicus 233), waarna hulle beheer daaroor verloor het. Die terme wat vir hierdie bekendmaking van literêre werke aan die publiek gebruik is, was ekdidónai (om weg te gee) en ékdosis (weggee. Vgl. uitgee, uitgewery). Dit was presies wat die proses behels het: die outeur het 
sy werk aan ander gegee om te lees, te kopieer en verder te versprei (Van Groningen, 1963:25; Easterling, 1985:19-20). Professionele kopiïste het die tekste in hulle scriptoria gekopieer, een op 'n slag of 'n paar tegelyk deur diktee, en aan die lewendige mark van lesers, skrywers en boekhandelaars op bestelling beskikbaar gestel.

Te midde van die groeiende oorheersing en verspreiding van die geskrewe gedig, beskou en noem die digter homself steeds 'sanger' en sy gedig 'lied' - 'n verskynsel wat tot vandag voortleef.

\begin{abstract}
In general the poctry of Alexandria reflects an intense interest in writing as a medium, especially in contrast to other media. ... The poetry of this age, then, constantly reaches beyond the medium of writing, perhaps most importantly in trying to recapture a sense of the occasions at which verse had once been performed. (Griffiths, 1979:25.)
\end{abstract}

Die digters skep dus in hulle tekste die illusie van 'n digter-sanger wat binne die konteks van 'n rituele geleentheid sy voordrag lewer (Griffiths, 1979:25-26). "If the poet is no longer a performer, he can at least dramatize himself as one on paper" (Griffiths, 1979:26).

\title{
3. Die konteks van kommunikasie
}

Vir die digter het dit beteken die vervanging van die eise van die geleentheid, tradisie en gehoor van die polis waarvan hy die spreekbuis was, deur die vryheid en individualisme van die hofkultuur en kosmopolitiese samelewing. Hy was nie meer die opvoeder of gewete of geheue van die gemeenskap nie; sy rol was nou baie meer sekulêr: om in die eerste plek homself en sy eksklusiewe gehoor van Griekse immigrante te vermaak en te leer (Bullock, 1985:543). Oor hierdie literêre produksie skryf Beye (1987:216):

Its reference was to the Greek world outside of Egypt and to the past. This colonial culture ignored the locals; as in other colonial cultures in other times, its creators were incestuous, introspective, clitist, and alienated. Instead of life lived, their preoccupation was with culture perceived (vgl. ook Bullock, 1985:543)

Die Alexandrynse digters was ook nie meer so eksplisiet in hulle geloof dat hulle die waarheid in pag gehad het of die mag sou hê om ander onsterflik te maak nie. Sulke mag was nou in die figure van die goddelike Ptolemeë versinnebeeld; die digter word dokumenteerder, die Muses "more ... librarians than ... goddesses" (Griffiths, 1979:1). "He spoke only for himself, for art, and for the rather superior values of the classical tradition" (Griffiths, 1979:1). Hierdie vervreemding tussen digters en volk, en die vertroeteling van die digters deur die Ptolemeërs is deur Timon van Phlios saamgevat in die beeld van voëls wat gevoed word, op papirus skryf, en eindeloos in die voëlkoue van die Muses redekawel (Athenaios 22D; Pfeiffer, 1968:97). Kallimachos self stel dit eksplisiet: "Ek verag alles van die volk" (Epigram 28.4 Pfeiffer; Griffiths, 1979:2).

Die Ptolemeërs het die politieke, godsdienstige en kulturele lewe beheer; die biblioteke en hulle kuratore het die verworwe kennis, die verlede, die tradisies bewaar. Die digter moes sy individualiteit en sy relevantheid op ander fondamente bou. Sy digkuns word 'n poësie van ontwyking, met verrassende vindingrykheid in vorm, tema en styl, en die benutting van velerlei 'stemme' om sy werklike posisie te vermom.

... the poet must learn the song of the cicada, a clear and lovely tone emanating from an invisible source ... It will continue to be the art of Proteus, that is, an art of metamorphosis and escape (Griffiths, 1979:50). 
Daar was egter formele, amptelike geleenthede waar poësie voorgedra is. Daar was eintlik 'n toename in amptelike spele, met gepaardgaande hoër koste en professionele kunstenaars (Tarn \& Griffith, 1978:113-115). Groot feeste is by Thespiai, Kos, Delphi, Magnesia en Miletos in siklusse van vier jaar elk gehou, en die vorste het 'n nuwe fees, die Ptolemaieia, in Alexandrië ingestel.

Die sumposion in die sale of tuine van die paleis van die heersende Ptolemaios of in die andron (kamer vir mans) in privaatwonings was een van die hooflokale vir die voordragte van poësie. Gepaste dekor in fresko's of mosaieke het die mure versier: plante (klimop, wingerd, vrugtebome), landelike tonele (rotse, grotte) en tuine. Daar is 'n beskrywing van Ptolemaios II Philadelphos se weelderige simposium-tuin in Athenaios (196D).

In 'n skyn-grafinskripsie ( $A P$ 7.415) verwys Kallimachos na die vermoë om 'n lied te komponeer, maar ook die kennis van 'wyn', dit wil sê die simposium. Dit is redelik om af te lei dat so 'n skyn-grafskrif by 'n simposium voorgedra kon word (Reitzenstein, 1893:87. 88). Die term epigrammata word ' $n$ versamelwoord vir etlike digters se paignia, speelse liedere by bankette: Hedulos (volgens Athenenaios 11.473A), Asklepiades (AP 12.50), Alkaios van Messene ( $A P$ 9.519), Asklepiades ( $A P$ 12.135; vgl. Hedulos, $A P$ 5.199; Reitzenstein, 1893:89-92). Athenaios (473A) verskaf die inligting dat Hedulos se epigramme tydens simposia voorgedra is. 'n Gedig in die Palatynse Antologie (7.444) verwys na 80 mense wat doodgebrand het tydens 'n simposium aan die huis van Antagoras. In Dioskorides, $A P 5.138$ sing 'n Atener tydens 'n simposium 'n monodie uit 'n tragedie.

Openbare kompetisie bestaan nog gedurende hierdie tydperk. Kallimachos se Epigram 8 is 'n gebed om oorwinning in 'n agôn, of poësiekompetisie. Die agôn wat so 'n dominante rol in die skepping en verspreiding van poësie in die ou Griekse stadstaat gespeel het (kyk Henderson, 1989:24-40), het in omvang toegeneem, maar nie in die eerste plek as milieu vir lewendige voordragte nie. Die oorspronklike doel het verander: in plaas van om 'die beste' te wees, wou deelnemers 'die eerste', dit wil sê die oorspronklikste wees (Schneider, 1967/69:I,55-56; kyk ook II, 189-198). Die werklike agonale drang is in die bewustelike literêre interaksie tussen digters bevredig. Theokritos se Idilles 13 en 22 vertoon literêre ooreenkonste met Apollonios se Argonautika boeke I (einde) en II (begin) wat die gevolg is van samewerking en wedywering in die intieme, geslote coterie van skrywers in die Mouseion (Beye, 1987: 262).

\section{Die aard van die kommunikasie}

Die fisieke ruimtes en kontekste waarbinne die Alexandrynse poësie geskep en gekommunikeer is, het onvermydelik die aard van die gekommunikeerde teks beinvloed en selfs bepaal. Die digter se teikengehoor was nou 'n beperkte kring van geletterde en gesofistikeerde lesers, waaronder ook lede van die hof van die Ptolemeër, en nie meer, soos in die tyd van die stadstaat, 'n gehoor van oorwegend ongeletterde toehoorders in 'n min of meer openbare ruimte nie. Die digter tree nie meer op as segsman van die stadstaat nie; hy praat nou namens homself (Susemihl, 1965:I,167-173; Couat, 1968:59-189; Webster, 1964:156-157; Schneider, 1967/69:1,78-117). Die bewuste literêre aard van die Alexandrynse poësie het die digter in 'n intellektuele spel met sy uitsoekgehoor/leser laat verkeer, en groot eise is aan die referensiewêreld van die teikengehoor gestel.

Onlangs het Hutchinson (1988:5-7) hierdie gesigspunt bevraagteken: die poësie het tog 
wyer uitgekring as die vorstelike hof. Dit is korrek: ons het reeds op die groter mate van geletterdheid in die Alexandrynse samelewing gewys. Ons kan ook sy waarskuwing aanvaar dat die teikengehoor se smak en belangstellings nie tot beperkende en verwringende kriteria vir die ontsluiting van die tekste verhef moet word nie. Dat die gehoor van die digters, en die aard en inhoud van hulle gedigte egter drasties verander het van wat dit in die 5 de eeu v.C. was, is telkemale bewysbaar vanuit die gedigte self. Die ware situasie is onlangs weer opnuut deur Goldhill (1991:223-224) geformuleer:

Social and intellectual exclusivity, then - however wide the readership for Alexandrian poetry is supposed to have been - is as integral to the contextualization of Hellenistic writing as the values and institutions of collectivity and openness are to fifth-century theatic.

Die beste digters was gedurig bewus van hierdie gehoor se verwagtings. Bullock (1985:543) wys daarop dat die uitsoekgehoor van die koninklike paleis, as eksklusiewe groep, 'n smaak vir die sensasionele en verfynde, die sentimentele en intellektuele vertoon het. Vanuit hulle geïsoleerde en verhewe posisie in die samelewing het hulle in die lae lewenswyses van stad en platteland, en in die gemeenplasige, vulgêre en selfs groteske behae geskep. Die alledaagse of realistiese eerder as die mitiese of heroïese of ideële word uitgebeeld. In taal en styl getuig hierdie gedigte van fyn, bewuste afwerking en tegniese vaardigheid, intellektuele spel en gevoelsanalise, en die ontginning van ironie en dubbelsinningheid.

In styl en vorm is hoë tegniese eise aan die digters gestel, waaraan die meeste uitstekend voldoen het. In 'n groot persentasie van die behoue gedigte oortref die tegniese vaardigheid egter die gehalte van die inhoud wat al te dikwels banaal en gewoon is. Die genres het patroonmatig geword en elke digter het sy vaardigheid ten toon gestel om binne die patroon die tema, styl of gevoel te varieer.

'n Belangstelling in nuwe kennis en geleerdheid (doctrina), 'n outomatiese inwerking van die akademiese atmosfeer in Alexandrië, kom in die poësie tot uiting. Byna al die digters in Alexandrië het ook in die biblioteek gewerk (Bullock, 1985:542-543). Die digters word self-bewus en intellektueel (Goldhill, 1991:224-225). Oral in die gedigte is verwysings na nuutverworwe kennis oor allerlei onderwerpe: geografie, volkstradisies, tegnologie, taalen literatuurwetenskap, filosofie en wetenskap, landbou, wiskunde en sterrekunde. Hierby moet. ingesluit word die groot belangstelling in en studie van die vroeëre digkuns. Die Alexandrynse digters het kreatief, herskeppend met hulle voorgangers omgegaan. Baie van hulle werk veronderstel kennis van die interteks, sodat die ironie en vindingrykheid van die nuwe teks gepeil kon word. Die doctus poeta is gebore.

Obskuriteit was dikwels die gevolg van hierdie beheptheid met geleerde verwysings, en dit is ook een van die punte van kritiek wat deur moderne geleerdes teen die Alexandryne gerig word. Die meeste van die geleerde verwysings lyk seker vir ons met ons beperkie bronne meer obskuur en ontoeganklik as wat dit was vir die uitsoekgehoor vir wie die gedigte oorspronklik bedoel was.

Beye (1987:269) verklaar hierdie element in die Alexandrynse poësie in terme van die koloniale mentaliteit van die Grieke in Egipte. Die geleerdheid en obskuriteit bind die lede van die geslote kring wat die 'kode' ken, saam, én skep 'n versperring teen nie-Grieke. Die groep word dus bewus gemaak en gehou van hulle kulturele identiteit. Die versameling boekrolle in die biblioteek was die repositorium van die Griekse kultuur wat in toenemende mate deur die nie-Griekse, biblioteeklose kulture bedreig is. 
Die resultaat was 'n kuns ter wille van die kuns (Couat, 1968:519-520). Die intense skeppingswerk en filologiese aktiwiteit is wel tot die biblioteke, die Mouseion en die hofsale beperk, maar die boek-georiënteerde kultuur is vir 'n wye gehoor deur die vryer beskikbaarheid van die boekrol oopgestel. Die oorheersend mondelinge kommunikasie en ervaring van die poësie in die ou stadstaat het plek gemaak vir geleesde werke. Letterkundige werke uit die skat van die tradisioneel-mondelinge skepping en van die nuwe literêre skepping is nou in die vorm van boekrolle uitgegee en gelees. Hierdie boekrolle is ook bestudeer en krities ontleed en bespreek - sodoende het die literatuurwetenskap begin.

\section{Bibliografie}

Beyc, C.R. 1987. Ancien Greek Literature and Society. 2nd revised edition. Ithaca-London : Cornell University Press.

Blum, R. 1977. Kallimachos und die Literaturverzeichnung bei den Griechen. Frankfurt am Main: Buchhändler-Verein.

Bullock, A.W. 1985. Hellenistic Poetry. In: Easterling \& Knox (eds.) p. 541-621.

Couat, A. 1968. La poésie alexandrine sous les trois premiers Ptolémées (324-222 av. J.-C.) Brussel : Culture et Civilisation (Paris 1882).

Davison, J.A. 1968. From Archilochus to Pindar. London-Melbourne-Toronto : Macmillan.

Easterling, P.E. 1985. Books and Readers in the Greek World: 2. The Hellenistic and Imperial Periods. In: Easterling \& Knox (eds.) :16-41.

Easterling, P.E. \& Knox, B.M.W. (eds.). 1985. The Cambridge History of Classical Literature, vol. 1: Greek Literature. Cambridge : University Press.

Goldhill, S. 1991. The Poet's Voice. Essays on Poetics and Greek Literature. Cambridge : University Press.

Griffiths, F.T. 1979. Theocritus at Court. Mncmosyne Suppl. 55. Leiden : Brill.

Henderson, W.J. 1989. Criteria in the Greck lyric contests. Mnemosyne, 42(1/2):24-40.

Herington, J. 1985. Poctry into Drama. Early Tragedy and the Greek Poctic Tradition. Sather Classical Lectures vol. 49. Berkeley : University of California Press.

Hutchinson, G.O. 1988. Hellenistic Poctry. Oxford : Clarendon Press.

Knox, B.M.W. 1985. Books and Readers in the Greek World: 1. From the Beginnings to Alexandria. In: Easterling \& Knox (eds.) p. 1-16.

Lesky, A. 1966. A History of Greek Literature (Transl. J. Willis \& C. de Heer). London : Mcthuen.

Pfeiffer, R. 1968. A History of Classical Scholarship from the Beginnings to the End of the Hellenistic Age. Oxford : Clarendon Press.

Reitzenstein, R. 1893. Epigramm und Skolion. Ein Beitrag zur Geschichte der alexandrinischen Dichtung. Giessen: J. Richier (neue Abdruck 1970, Hildesheim : Georg Olms).

Schneider, C. 1967/69. Kulturgeschichte des Hellenismus, 2 vols. München : C.H. Beck.

Susemihl, F. 1965. Geschichte der griechischen Literatur in der Alexanderzeit. 2 vols. Hildesheim : Georg Olms (Leipzig 1891-92).

Tarn, W.W. \& Griffith, G.T. 1978. Hellenistic Civilisation. London : Methuen.

Van Groningen, B.A. 1963. Traité d'histoire et de critique des textes grecs. Amsterdam : Noord-Holland.

Webster, T.B.L. 1964. Hellenistic Poetry and Ant. London : Methuen.

Wright, F.A. 1932. A History of Later Greek Literature from the Death of Alexander in 323 B.C. to the Death of Justinian in 565 A.D. London : Routledge.

\section{Randse Afrikaanse Universiteit}

